\title{
Unemployment rate as predictor of rate of psychiatric admission
}

\author{
Robert M Kammerling, Susan O'Connor
}

\begin{abstract}
Objective-To examine the relation between rates of psychiatric admissions and both the rate of unemployment and the underprivileged area score within small areas.

Design-Calculation of correlation coefficients and explanatory power by using data on psychiatric admissions from April 1990 to March 1992. Crude and age standardised rates were used based on all admissions and also on the number of people admitted regardless of the number of times each person was admitted.
\end{abstract}

Setting-Sectors with an average population of 45000 consisting of aggregations of neighbouring wards in Bristol and District Health Authority and electoral wards with an average population of 9400 in the city of Bristol.

Results-Unemployment rates explained $93 \%$ of the variation in the crude person based admission rates standardised for age for those aged under 65 in the sectors. Person based rates correlated more strongly with unemployment than did rates based on all separate admissions. Inclusion of people aged 65 and over weakened the relation. Within electoral wards unemployment rates explained only about $50-60 \%$ of the variation but were still more powerful than the underprivileged area score. There was a significant negative correlation between average length of stay and readmission rates-that is, sectors with short lengths of stay were more likely to have patients readmitted $(r=-0.64,95 \%$ confidence interval -0.25 to -0.85 ).

Conclusions-Unemployment rates are an extremely powerful indicator of the rates of serious mental illness that will need treatment in hospital in those aged under 65 . This should be considered in the process of resource allocation, particularly to fundholders in general practice, or people with serious mental illness living in areas of high unemployment could be considerably disadvantaged.

\section{Introduction}

The association between socioeconomic status and admissions to hospital for mental illness has been recognised for 50 years.' The ways in which this relation could assist planners in the health service in identifying differing needs for psychiatric beds between different areas were studied in detail by the Royal College of Psychiatrists. ${ }^{2}$ It reported some evidence of a correlation between the uptake of mental health services and unemployment and described several studies confirming the close relation between social deprivation and admission rates. The use of the underprivileged area score devised by Jarman was recommended as the measure of social deprivation to be used. A later study looked at the correlation between underprivileged area scores and psychiatric admission rates in 185 districts nationally and claimed to confirm its usefulness. ${ }^{3}$

The importance of identifying objective factors which relate to use of services has been emphasised by the recent addition of some mental health services to the range of health care to be purchased by fundholders in general practice. ${ }^{4}$ If there is a substantial variation in need for services related to identifiable socioeconomic factors in the population served by different general practices a budget setting process which does not take this into account may distort the ability of services to respond to those patients in greatest need.

In a comparison of the underprivileged area score with other indices of socioeconomic status (including unemployment rates) the underprivileged area score was consistently outperformed, in terms of its correlation with general measures of morbidity, by unemployment rates. ${ }^{5}$

We compared the relation of the use of psychiatric beds to unemployment rates and the underprivileged area score within Bristol and District Health Authority by small areas.

\section{Methods}

Bristol and District Health Authority was created in 1991 from the merger of three previous health authorities. It covers the city of Bristol and a large part of the county of Avon. It serves a population of 820000 people.

Information about each psychiatric admission to a hospital in the South Western Regional Health Authority was available through a computer link to the regional computer centre. The information we studied included hospital number, age, sex, local authority ward of residence, diagnosis, and length of admission in days. Only patients resident in Bristol and district were included.

The district had previously been divided into 18 sectors for epidemiological analysis, each sector consisting of groupings of neighbouring wards, which attempted to reflect natural communities in the district but were large enough to produce sufficient numbers of health related events to allow meaningful statistical analysis. A further limiting factor was the need to have detailed projections of population numbers regularly updated for each sector. These were obtained from Avon County Council and were available at ward level for the city of Bristol but only at a much higher level of aggregation outside the city. In one case sufficiently detailed projections were not available at lower than district council level. The population of the sectors therefore varied between 23000 and 95000 , the average being 45000 .

Estimates of unemployment rates at ward level, based on Department of Employment statistics, were provided by Avon County Council. These were aggregated up to the sectors and averaged across the two years by using data from April 1990, October 1990, April 1991, October 1991, and April 1992.

An episode was counted as an admission to hospital in the specialty of mental illness between 1 April 1990 and 30 March 1992. Age standardised admission ratios were calculated in a way analogous to the calculation of standardised mortality ratios by using the whole district population as a standard and counting each separate episode.

We also used the hospital number to identify people who were admitted more than once and calculated the person based standardised admission ratios: a measure of the number of separate people admitted from an area regardless of the number of times each person was 
admitted. The standardised admission ratios were calculated separately for all ages and for people under 65 years. Crude admission rates were also calculated for all episodes and based on the number of people admitted and also for all ages and for those aged under 65.

Readmission ratios were calculated by dividing the number of episodes by the number of people who made up those episodes. Length of stay was calculated both as average length of stay per episode, excluding all patients who were still in hospital on 31 March 1992, and as an average of total days spent in hospital by each person over the two years, regardless of whether the days were accumulated over one or several episodes. Distance from the nearest acute beds was measured as a straight line on a map between the site of the beds and the centre of the small area.

All standardised admission ratios were recalculated for wards in Bristol city. There were 34 such wards, with an average population of 9400 . As well as unemployment rates we obtained further socioeconomic data from the 1981 census. These included the underprivileged area score and the values of the individual elements which make up the score.

\section{Results}

During the period studied 4109 different people were admitted to mental health institutions, but TABLE I-Ranges of population values and admissions to psychiatric hospital within small areas in Bristol and Avon

\begin{tabular}{|c|c|c|c|}
\hline Category & $\begin{array}{c}\text { Lowest } \\
\text { (95\% confidence } \\
\text { interval) }\end{array}$ & $\begin{array}{c}\text { Highest } \\
\text { (95\% confidence } \\
\text { interval) }\end{array}$ & District \\
\hline $\begin{array}{l}\text { Total No in } \\
\text { population: }\end{array}$ & 22950 & 94580 & 817550 \\
\hline $\begin{array}{c}\text { Total No aged } \\
<65 \text { years }\end{array}$ & 19320 & 82750 & 684204 \\
\hline \multicolumn{4}{|c|}{ All admissions } \\
\hline \multicolumn{4}{|l|}{ No: } \\
\hline All ages & 119 & 576 & 6096 \\
\hline$<65$ years & 73 & 423 & 4109 \\
\hline \multicolumn{4}{|c|}{ Crude rate per $1000:$} \\
\hline $\begin{array}{l}\text { All ages } \\
<65 \text { years }\end{array}$ & $\begin{array}{l}35(29 \text { to } 41) \\
24(20 \text { to } 27)\end{array}$ & $\begin{array}{l}165(150 \text { to } 180) \\
178(161 \text { to } 195)\end{array}$ & $\begin{array}{l}76 \\
60\end{array}$ \\
\hline \multicolumn{4}{|c|}{ Standardised ratio: } \\
\hline $\begin{array}{l}\text { All ages } \\
<65 \text { years }\end{array}$ & $\begin{array}{l}46(38 \text { to } 54) \\
39(34 \text { to } 45)\end{array}$ & $\begin{array}{l}219(199 \text { to } 239) \\
299(271 \text { to } 328)\end{array}$ & $\begin{array}{l}100 \\
100\end{array}$ \\
\hline \multicolumn{4}{|c|}{ Person based } \\
\hline No: & & & \\
\hline All ages & 76 & 393 & 4012 \\
\hline$<65$ years & 53 & 270 & 2680 \\
\hline \multicolumn{4}{|c|}{ Crude rate per 1000 : } \\
\hline All ages & $25(19$ to 30$)$ & $107(95$ to 119$)$ & 49 \\
\hline \multicolumn{3}{|c|}{ Standardised ratio: } & \\
\hline All ages & 48 (38 to 58$)$ & 215 (191 to 239 ) & 100 \\
\hline$<65$ years & 44 (35 to 53$)$ & 293 (258 to 328$)$ & 100 \\
\hline
\end{tabular}

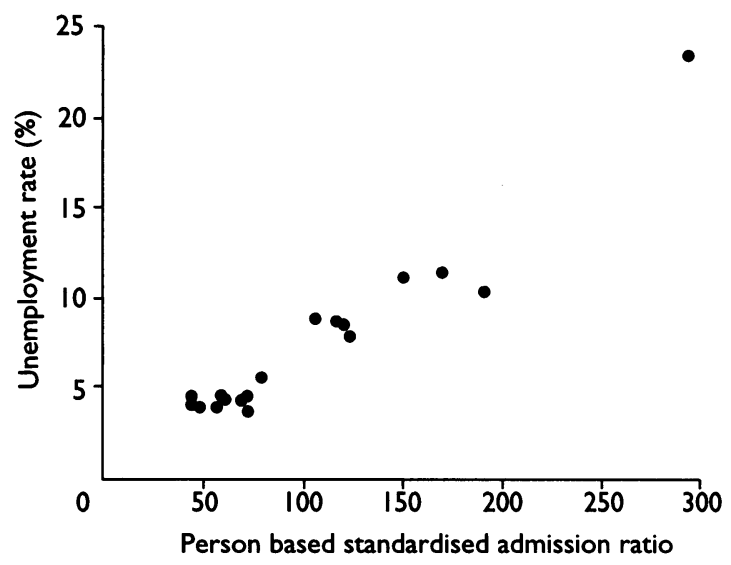

Relation between average unemployment rate and person based psychiatric admission ratio for people under 65 years, 1 April 1990 to 31 March 1992

because some people were admitted more than once there were a total of 6096 admission episodes. Overall, $148(2 \cdot 4 \%)$ admissions and $98(2 \cdot 4 \%)$ people could not be allocated to an electoral ward and were excluded from further analysis. Of the remaining admissions, 321 people were still in hospital on 31 March 1992 and were excluded from the analysis of lengths of stay.

Table I shows the range of admissions, rates, and standardised ratios with the confidence intervals and the district values. The ratio between the lowest and highest values varied between about 4.5 when all ages were considered and $7 \cdot 5$ for the under $65 \mathrm{~s}$.

The figure shows the relation at small area level between the person based admission ratios for the under 65 s and unemployment. There is one obvious outlier, exceptional for both a very high rate of unemployment and a very high rate of admissions.

There was a remarkably strong correlation between admission rates, however calculated, and unemployment rates. Table II shows the Pearson correlation coefficients between the different ways of calculating treatment rates and unemployment, length of stay, readmisison ratios, and distance from the nearest acute unit (for the under 65s only), including and excluding the outlier. Unemployment alone explained $88 \%$ of the variation in person based rates and $93 \%$ of the variation in these rates for the under $65 \mathrm{~s}$ (calculated from the square of the correlation coefficient). Person based rates, whether expressed as crude rates or standardised ratios, had a slightly stronger correlation than rates calculated by counting each admission episode separately. The exclusion of the outlier made little difference.

There were no significant correlations between the

TABLE II-Correlation coefficient ( $r$ ) between admission rates and other factors (95\% confidence intervals) by sector, Bristol and District Health Authority

\begin{tabular}{|c|c|c|c|c|c|}
\hline Ratio/rate & Unemployment rates & Average length of stay & $\begin{array}{l}\text { Total days in hospital } \\
\text { per person }\end{array}$ & Readmission ratios & Distance from acute bed \\
\hline \multicolumn{6}{|c|}{ Person based } \\
\hline \multicolumn{6}{|c|}{ Standardised admission ratio: } \\
\hline All ages & $0.94(0.83$ to 0.98$)$ & $-0.32(-0.68$ to 0.18$)$ & $0.10(-0.39$ to 0.54$)$ & $0.40(-0.08$ to 0.73$)$ & $-0.17(-0.59$ to 0.33$)$ \\
\hline Excluding outlier & $0.92(0.79$ to 0.97$)$ & $-0.25(-0.64$ to 0.24$)$ & $0.10(-0.36$ to 0.54$)$ & $0.45(-0.02$ to 0.76$)$ & $-0.21(-0.62$ to 0.28$)$ \\
\hline$<65$ years & $0.96(0.90$ to 0.99$)$ & $-0.35(-0.70$ to 0.14$)$ & $0.03(-0.44$ to 0.49$)$ & $0.41(-0.07$ to 0.74$)$ & $-0.16(-0.59$ to 0.33$)$ \\
\hline Excluding outlier & $0.93(0.83$ to 0.98$)$ & $-0.31(-0.68$ to 0.18$)$ & $0.01(-0.46$ to 0.48$)$ & $0.49(0.03$ to 0.78$)$ & $-0.23(-0.63$ to 0.27$)$ \\
\hline \multicolumn{6}{|l|}{ Crude rates: } \\
\hline All ages & $0.93(0.82$ to 0.97$)$ & $-0.30(-0.67$ to 0.19$)$ & $0.08(-0.40$ to 0.53$)$ & $0.38(-0.11$ to 0.72$)$ & $-0.14(-0.57$ to 0.35$)$ \\
\hline Excluding outlier & $0.92(0.80$ to 0.97$)$ & $-0.22(-0.63$ to 0.27$)$ & $0.08(-0.40$ to 0.53$)$ & $0.41(-0.07$ to 0.74$)$ & $-0.17(-0.59$ to 0.32$)$ \\
\hline$<65$ years & $0.96(0.90$ to 0.99$)$ & $-0.35(-0.70$ to 0.13$)$ & $0.03(-0.44$ to 0.49$)$ & $0.41(-0.07$ to 0.74$)$ & $-0.17(-0.59$ to 0.32$)$ \\
\hline Excluding outlier & $0.94(0.83$ to 0.96$)$ & $-0.32(-0.66$ to 0.18$)$ & $0.01(-0.46$ to 0.47$)$ & $0.49(0.03$ to 0.78$)$ & $-0.23(-0.63$ to 0.26$)$ \\
\hline \multicolumn{6}{|c|}{ Admission based } \\
\hline \multicolumn{6}{|c|}{ Standardised admission ratio: } \\
\hline All ages & $0.93(0.82$ to 0.97$)$ & $-0.39(-0.73$ to 0.09$)$ & $0.07(-0.41$ to 0.52$)$ & $0.53(0.09$ to 0.80$)$ & $-0.20(-0.61$ to 0.30$)$ \\
\hline Excluding outlier & $0.93(0.82$ to 0.97$)$ & $-0.36(-0.71$ to 0.13$)$ & $0.07(-0.41$ to 0.52$)$ & $0.61(0.20$ to 0.84$)$ & $-0.25(-0.64$ to 0.25$)$ \\
\hline$<65$ years & $0.95(0.87$ to 0.98$)$ & $-0.40(-0.73$ to 0.09$)$ & $-0.01(-0.47$ to 0.46$)$ & $0.47(0.00$ to 0.77$)$ & $-0.14(-0.57$ to 0.35$)$ \\
\hline Excluding outlier & $0.92(0.79$ to 0.97$)$ & $-0.37(-0.37$ to 0.12$)$ & $-0.04(-0.50$ to 0.44$)$ & $0.57(0.13$ to 0.82$)$ & $-0.19(-0.60$ to 0.30$)$ \\
\hline \multicolumn{6}{|l|}{ Crude rate: } \\
\hline All ages & $0.93(0.81$ to 0.97$)$ & $-0.38(-0.72$ to 0.11$)$ & $0.05(-0.42$ to 0.51$)$ & $0.51(0.06$ to 0.79$)$ & $-0.17(-0.59$ to 0.32$)$ \\
\hline Excluding outlier & $0.94(0.83$ to 0.96$)$ & $-0.33(-0.69$ to 0.16$)$ & $0.04(-0.43$ to 0.50$)$ & $0.57(0.15$ to 0.82$)$ & $-0.21(-0.62$ to 0.28$)$ \\
\hline$<65$ years & 0.95 (0.87 to 0.98$)$ & $-0.39(-0.73$ to 0.09$)$ & $0.00(-0.47$ to 0.46$)$ & $0.47(0.01$ to 0.77$)$ & $-0.14(-0.57$ to 0.35$)$ \\
\hline Excluding outlier & $0.92(0.79$ to 0.97$)$ & $-0.37(-0.72$ to 0.11$)$ & $-0.04(-0.50$ to 0.43$)$ & $0.57(0.14$ to 0.82$)$ & $-0.19(-0.61$ to 0.30$)$ \\
\hline
\end{tabular}


TABLE III-Correlation coefficient $(r)$ between admission rates and other factors (95\% confidence intervals) by ward, Bristol city

\begin{tabular}{|c|c|c|c|c|c|}
\hline Ratio/rate & $\begin{array}{l}\text { Unemployment } \\
\text { rates }\end{array}$ & $\begin{array}{l}\text { Underprivileged area } \\
\text { score }\end{array}$ & $\begin{array}{l}\text { Average length } \\
\text { of stay }\end{array}$ & $\begin{array}{l}\text { Total days in hospital } \\
\text { per person }\end{array}$ & Readmission ratios \\
\hline \multicolumn{6}{|c|}{ Person based } \\
\hline \multicolumn{6}{|c|}{ Standardised admission ratio: } \\
\hline All ages & $0.78(0.49$ to 0.91$)$ & $0.66(0.29$ to 0.86$)$ & $-0.25(-0.64$ to 0.24$)$ & $0.09(-0.40$ to 0.53$)$ & $0.18(-0.31$ to 0.60$)$ \\
\hline$<65$ years & $0.82(0.57$ to 0.93$)$ & $0.73(0.39$ to 0.89$)$ & $-0.28(-0.66$ to 0.22$)$ & $0.00(-0.47$ to 0.46$)$ & $0.20(-0.29$ to 0.61$)$ \\
\hline \multicolumn{6}{|l|}{ Crude rate: } \\
\hline All ages & $0.76(0.46$ to 0.91$)$ & $0.65(0.26$ to 0.86$)$ & $-0.22(-0.62$ to 0.27$)$ & $0.10(-0.38$ to 0.54$)$ & $0.17(-0.32$ to 0.59$)$ \\
\hline$<65$ years & $0.82(0.57$ to 0.93$)$ & $0.72(0.39$ to 0.89$)$ & $-0.28(-0.66$ to 0.22$)$ & $0.00(-0.47$ to 0.46$)$ & $0.21(-0.29$ to 0.61$)$ \\
\hline \multicolumn{6}{|c|}{ Admission based } \\
\hline \multicolumn{6}{|c|}{ Standardised admission ratio: } \\
\hline All ages & $0.80(0.54$ to 0.92$)$ & $0.68(0.32$ to 0.87$)$ & $-0.37(-0.71$ to 0.12$)$ & $0.09(-0.39$ to 0.54$)$ & $0.46(-0.01$ to 0.76$)$ \\
\hline$<65$ years & $0.84(0.61$ to 0.94$)$ & $0.73(0.41$ to 0.89$)$ & $-0.32(-0.68$ to 0.17$)$ & $-0.03(-0.49$ to 0.44$)$ & $0.32(-0.17$ to 0.69$)$ \\
\hline \multicolumn{6}{|l|}{ Crude rate: } \\
\hline All ages & $0.80(0.53$ to 0.92$)$ & $0.67(0.30$ to 0.87$)$ & $-0.35(-0.70$ to 0.14$)$ & $0.11(-0.38$ to 0.55$)$ & $0.46(-0.01$ to 0.76$)$ \\
\hline$<65$ years & $0.84(0.61$ to 0.94$)$ & $0.73(0.40$ to 0.89$)$ & $-0.32(-0.68$ to 0.17$)$ & $-0.03(-0.49$ to 0.45$)$ & $0.33(-0.17$ to 0.69$)$ \\
\hline
\end{tabular}

admission rates for all sectors, however calculated, and any of the other factors. There was a significant negative correlation $(r=-0.64,95 \%$ confidence interval -0.25 to -0.85 ) between average length of stay and readmisison ratios-that is, areas with short lengths of stay were more likely to readmit patients.

When we looked at individual wards in Bristol city (table III) the correlations between admission rates and unemployment remained significant but were substantially weaker, explaining only about $50-60 \%$ of the variation between wards. The correlation was stronger than that between the admission rates and the underprivileged area score $(0.79 v 0.71$ for person based ratios in the under $65 \mathrm{~s}$ ).

When we examined the individual elements that made up the underprivileged area score there was a significant correlation between the person based admission ratios and the percentage of people who had moved in the previous year $(r=0.46,0.15$ to 0.69$)$ and the percentage of people who were from ethnic minorities $(r=0.61,0.35$ to 0.78$)$. When ethnic group was added to the average unemployment rates between April 1990 and April 1992 in a multiple regression model, however, the explanatory power of the model went from $53 \%$ (unemployment alone) to $54 \%$ (unemployment and ethnic group).

\section{Discussion}

The relation between socioeconomic factors and admission to psychiatric hospital has long been recognised, ${ }^{6}$ and the possibility of a correlation between unemployment and the uptake of mental health services is not new. ${ }^{7}$

What is surprising about our analysis is the power of the relation, with unemployment rates alone explaining over $90 \%$ of the variation in standardised admission ratios. The Royal College of Psychiatrists reported a correlation between Jarman scores and admission rates of about 0.8 - that is, explaining only about $64 \%$ of the variation. ${ }^{3}$ Jarman et al were able to explain only $34 \%$ of the variation in admission rates between districts standardised for age, sex, and marital status and $23 \%$ of the variation in crude rates. ${ }^{3}$

\section{REASONS FOR POWERFUL RELATION}

There are several possible explanations for the added strength of the relation we found. Firstly, with the advent of charging mechanisms in the NHS there is probably a more accurate identification of a patient's district of residence than previously. Secondly, our explanatory variable, unemployment, covered exactly the same period as our admission data rather than being derived from out of date census information. Thirdly, we were able to count the number of individual people as well as the total number of admissions. This clearly eliminates some of the confounding caused by readmissions, although some double counting could still have occurred in respect of people who transferred between hospitals, thus changing their hospital number. Fourthly, by using sectors rather than wards and combining two years of data we had numbers of admissions within sectors substantially larger than those found in ward based studies. When we analysed our data at a ward level for Bristol city we found correlations similar to those reported elsewhere, suggesting our findings are consistent with others. Finally, we used age as a dividing line for our calculations and found no correlation between unemployment rates and treatment rates in people over 65 , as shown by the reduction in the $r$ value when they were included. Thus, any analysis which includes people over this age is likely to underestimate the power of the relation.

A complex model derived from nine census variables has been shown to achieve an explanatory power almost identical with ours, ${ }^{8}$ again suggesting our results are consistent with those found elsewhere.

Although differences in admission rates may reflect differences in need between areas, other explanations must be considered. Because other hospitals need to notify Bristol and District Health Authority of treatments provided to residents of the district we are confident that we have missed only a trivial proportion of hospital admissions. Some admissions, particularly in the socially advantaged areas, may have occurred in the private sector. Again, we consider the effects of this to have been marginal: the area is not well served by private facilities for mental illness.

We do not think that the differences were the result of different services available in different parts of the district. The district was served by three units with acute admission beds, each unit having a well defined catchment area. An examination of sectors within each of these catchments separately showed that each unit served areas with both high and low admission ratios. If the four sectors with both the highest admission ratios and unemployment rates were excluded, all being served by the same unit, the range of admission ratios looked similar in all three catchments.

Although there were differences in average length of stay per admission and the readmission ratios, suggesting differences in clinical management, the absence of any significant correlation between the total days spent in hospital per person and the admission ratios suggests that these differences did not significantly affect the number of people treated.

\section{PREVIOUS STUDIES}

The nature of the relation between unemployment and admission to mental health beds was considered by the Royal College of Psychiatrists. ${ }^{2}$ It did not suggest that there was any direct correlation between measures of mental health in the population and unemployment; it suggested, for example, that the relation might reflect a greater opportunity to obtain treatment.

There is, however, some evidence to support a direct relation between unemployment and poor mental 


\section{Public health implications}

- The relation between the socioeconomic status of an area and the number of psychiatric admissions is well established

- Unemployment rates are a useful marker for socioeconomic deprivation

- This study found a sevenfold variation between small areas in the rates of people under 65 admitted to psychiatric hospitals

- There was a very powerful correlation between the psychiatric admission ratios in those aged under 65 and unemployment rates, explaining over $90 \%$ of this variation

- This should be considered in the process of allocating resources to areas otherwise people with serious mental illness could be considerably disadvantaged patients. ${ }^{14}$ We therefore suggest that this study confirms the view that the unemployment rate in an area reflects its socioeconomic status, which has a profound effect on its need for inpatient psychiatric care.

Some account is already taken of deprivation in resource allocation, with the underprivileged area score being used to allocate enhanced capitation fees to general practitioners working in deprived areas. Within Bristol and District Health Authority the range of the variation between sectors in psychiatric admissions was far greater than in any other major specialty. If, as seems likely, this variation reflects genuine differences in morbidity between areas then clearly this should be considered separately in allocation of resources. This is a particularly important issue now that fundholders in general practice can purchase some elements of local mental health services. Because of their magnitude, unless such variations are specifically taken into account patients living in areas of poor socioeconomic status could be severely disadvantaged.

development of depression and other psychiat orders after substantial periods of unemployment. ${ }^{9-11}$

In community surveys in America, however, Kessler et al showed that lack of income is the component of low socioeconomic status that most strongly influences exposure to negative events. ${ }^{12}$ Their findings also suggest that the extent to which a person reacts negatively to these events is influenced by education and occupation. Furthermore, unemployment is also more common in certain groups within society-for example, unmarried, unskilled, or semiskilled people and those who earn comparatively low wages when employed. ${ }^{13}$

Whether the relation we observed was due to increased admissions among unemployed people or to other reasons is unclear. However, we identified no significant changes in the numbers of admissions or lengths of stay during the two years we studied, despite a doubling of the unemployment rates during the period.

The use of unemployment rates has been proposed as a simple up to date marker for deprivation. ${ }^{5}$ The explanatory power we found was remarkably similar to that derived from a complex blend of census variables reflecting deprivation ${ }^{8}$ and to that between unemployment and the rate of admisson of new long stay
1 Faris REL, Dunham HW. Mental disorders in urban areas. Chicago: Hafner, 1939.

2 Royal College of Psychiatrists. Psychiatric beds and resources: factors influencing bed use and service planning. London: Gaskell, 1988.

3 Jarman B, Hirsch S, White P, Driscoll R. Predicting psychiatric admission rates. $B M F$ 1992;304:1146-5.

4 Health Care Directorate (Service Development), NHSME. General practice funding: guidance on the extension of the hospital and community health services elements of the GP fundholding scheme from 1 April 1993. London: NHSME, 1992. (Issued under cover of EL (92) 48.)

5 Campbell DA, Radford JMC, Burton P. Unemployment rates; an alternative to the Jarman index? $B M F$ 1991:303:750-5.

Hare EH. Mental illness and social conditions in Bristol. fournal of Mental Science 1956; 102:349-57.

7 Warr PB. Work, unemployment and mental health. Oxford: Clarendon Press, 1987.

8 Thornicroft G. Social deprivation and rates of treated mental disorder. $\mathrm{Br} \mathcal{F}$ Psychiatry 1991;158:475-84.

9 Bolton W, Oatley K. A longitudinal study of social support and depression in unemployed men. Psychol Med 1987;17:453-60.

10 Melville D, Hope D, Bennison D, Barraclough B. Depression among men made involuntarily redundant. Psychol Med 1985;15:789-93.

11 Eales MJ. Depression and anxiety in unemployed men. Psychol Med 1988;18:935-45.

12 Kessler RC, Turner JB, Hoare JS. Unemployment and emotional functioning in a community sample. American Sociology Review 1989;24:648-57.

13 Newton J. Preventing mental illness. Routledge: London, 1988.

14 Thornicroft G, Margolius O, Jones D. The TAPS project 6: new long stay psychiatric patients and social deprivation $B r \mathcal{F}$ Psychiatry 1992;161:621-4.

(Accepted 1 October 1993)

\section{Screening migrants at risk of tuberculosis}

\author{
R M Hardie, J M Watson
}

Public Health Laboratory

Service, Communicable

Disease Surveillance

Centre, London NW9 5EQ

R M Hardie, registrar in

public health medicine

$\mathrm{J} M$ Watson, consultant

epidemiologist

Correspondence to:

Dr Hardie.

$B M F$ 1993;307:1539-40
Nearly half the notifications of tuberculosis in England and Wales occur in people born abroad. In those born in countries with a high prevalence of tuberculosis notification rates are highest in the five years after entry into the United Kingdom. ${ }^{1}$ Notification rates declined in all ethnic groups in England and Wales up to the mid-1980s, but since then the decline in annual notifications has stopped and in some years the number of notifications has actually increased. ${ }^{12}$

Newly arrived migrants who might benefit from screening for tuberculosis should be referred to health control units at their port of arrival; the control unit should then notify the migrant's destination district so that follow up can be arranged. But only a third of migrants are referred to port health control units (figure), and, of those referred, many are lost to follow up at district level. ${ }^{3}$ Districts are recommended to use additional methods to identify migrants. ${ }^{4} \mathrm{We}$ performed a survey to determine the methods used by district health authorities to identify and screen newly arrived migrants for tuberculosis.

\section{Methods and results}

A questionnaire was sent to consultants in communicable disease control in 50 randomly selected districts in England and Wales in February 1992 asking whether they had written policies for screening migrants for tuberculosis, the methods they used to identify migrants, and how they screened them. Forty five districts replied. Nineteen had a written policy for screening migrants for tuberculosis. Forty three districts used the port of arrival system and eight used additional methods to identify migrants. Within these eight districts the principal methods were liaison with schools, family health services authorities, social services, and community groups. Six districts reported finding 0-100 additional migrants in this way, but one, using three supplementary methods, identified over 100 migrants more than those referred from the port of arrival (50-200 a year). Initial screening took place in the migrant's home in 31 districts, in chest medicine clinics in 36 districts, and in a clinic for new migrants in six.

For migrants referred using form port 102 (figure) chest $x$ ray examinations were used for screening by 37 